\title{
DIÁLOGO E TOLERÂNCIA COMO VALORES IMPORTANTES PARA A ARTE DE APRENDER A VIVER JUNTOS.
}

\author{
Angélica Ferreira Ribeiro' ${ }^{1}$ Augusta Boa Sorte O. Klebis ${ }^{2}$, Carmen Lúcia Dias ${ }^{3}$ \\ Universidade do Oeste Paulista - UNOESTE, Programa de Pós-Graduação em Educação (PPGE), Presidente Prudente, \\ SP. E-mail: arturshalom@hotmail.com.br.
}

\section{RESUMO}

Este artigo apresenta reflexões sobre diálogo e tolerância como pontos a serem considerados para uma boa convivência. O objetivo geral é discutir a contribuição do diálogo e tolerância como valores fundamentais para a arte de aprender a viver juntos. Especificamente, propõe: a) refletir sobre a importância do diálogo e tolerância nas diferentes formas de convívio; b) discutir possíveis ações que impulsionam o ser humano a colocar em prática, diálogo e tolerância. Trata-se de uma abordagem qualitativa, cuja opção metodológica foi pela pesquisa bibliográfica. Entende-se que o aprender a conviver exige que se rompa com a visão de uma cultura hegemônica e assim caminhar em direção à valorização da interculturalidade, no respeito e reconhecimento do outro. As diferenças sempre existirão, é preciso saber conviver harmoniosamente, procurando vencer o preconceito, compreendendo e respeitando o próximo. Há muito que se aprender com as diferentes formas de manifestações culturais.

Palavras Chave: Diálogo. Tolerância. Valores. Convivência.

\section{DIALOGUE AND TOLERANCE AS IMPORTANT VALUES FOR THE ART OF LEARNING TO LIVE TOGETHER.}

\begin{abstract}
This article presents reflections on dialogue and tolerance as points to be considered for a good coexistence. The overall goal is to discuss the contribution of dialogue and tolerance as core values for the art of learning to live together. Specifically, it proposes: a) to reflect on the importance of dialogue and tolerance in the different forms of conviviality; b) discuss possible actions that encourage the human being to put into practice, dialogue and tolerance. It is a qualitative approach, whose methodological option was the bibliographical research. It is understood that learning to live together requires that one break with the vision of a hegemonic culture and thus move towards the valorization of interculturality, in the respect and recognition of the other. The differences will always exist, it is necessary to know how to live harmoniously, seeking to overcome prejudice, understanding and respecting others. There is much to learn from the different forms of cultural manifestation.
\end{abstract}

Keywords: Dialogue. Tolerance. Values. Coexistence. 


\section{INTRODUÇÃO}

A intenção deste artigo é apresentar uma perspectiva sobre a convivência humana, baseada na importância do diálogo e da tolerância como valores importantes para a arte de aprender a viver juntos. Partindo do pressuposto que o diálogo e a tolerância são fatores imprescindíveis, uma vez que em toda e qualquer forma de convívio humano, é preciso prezar por situações que conduzam o indivíduo a um bom relacionamento. Nesse sentido, entende-se como necessária uma reflexão sobre a educação em valores, bem como sobre os quatro pilares da educação, propostos pela UNESCO: “[...] aprender a conhecer, aprender a fazer; aprender a viver juntos; aprender a ser" (DELORS, 2006, p. 90). O artigo busca, portanto, enfatizar de forma significativa o aprender a viver juntos.

Desde os primórdios o ser humano procurou caminhos em busca de uma "boa convivência". Entende-se que algumas formas de convivência como o diálogo e tolerância são ações voltadas aos valores morais, portanto, pontos consideráveis para que democraticamente se aprenda a viver socialmente.

O presente artigo relata uma pesquisa bibliográfica, de abordagem qualitativa que delineou como objetivo geral discutir a contribuição do diálogo e tolerância como valores fundamentais para a arte de aprender a viver juntos. Especificamente, propõe: a) refletir sobre a importância do diálogo e tolerância nas diferentes formas de convívio; b) discutir possíveis ações que impulsionam o ser humano a colocar em prática, diálogo e tolerância.

\section{METODOLOGIA}

Conforme já citado, o estudo em questão possui uma abordagem qualitativa, cuja opção metodológica foi pela pesquisa bibliográfica que buscou incursionar na produção de alguns autores que discutem o tema e em documentos oficiais pertinentes.

Para Marconi e Lakatos (1999, p. 43, 44), "o universo de uma pesquisa depende do assunto a ser investigado, e a amostra, porção ou parcela do universo, que realmente será submetida à verificação". Os autores ressaltam ainda a importância de se delimitar a pesquisa, ou seja, estabelecer um recorte para a investigação por não ser possível a um indivíduo dominar a totalidade do assunto pesquisado. Dessa forma, torna-se necessário selecionar o que pode ser tratado com mais profundidade, uma vez que este artigo não tem por presunção esgotar ou esclarecer totalmente o tema proposto, mas sim apresentar alguns marcadores de reflexão.

Portanto, com base em pesquisas de autores diversos que apresentam os fundamentos filosóficos e pedagógicos, esse estudo busca discutir a importância de uma educação em valores no ensino para a construção de uma sociedade que valorize o diálogo e a tolerância como promotores para uma boa convivência.

\section{DIÁLOGO E TOLERÂNCIA NAS RELAÇÕES SOCIAIS}

É importante mencionar que diálogo é uma conversação entre duas ou mais pessoas. Embora se desenvolva a partir de pontos de vista diferentes, o diálogo propõe um clima de boa vontade e compreensão recíproca.

Tolerância é entendida como a permissão e o respeito para com a maneira de pensar e a forma de viver dos outros. Eticamente, fundamenta-se na dignidade e na liberdade de consciência de cada homem.

Conforme Pérez Serrano (2002, pg. 39): "a tolerância surge quando nos importam as diferenças existentes entre os homens e os povos e nós as aceitamos como um enriquecimento." Não se deve ignorar o próximo com suas particulares ações, são essas ações que darão sentido e valor a diferença. Sendo assim, a tolerância vai além do estar juntos, é compreender que a diferença existente no outro pode nos enriquecer, permitindo reconhecer o próximo como alguém que faz parte de um mundo pertencente a todos. A tolerância pode ser entendida como uma 
virtude ativa que anima e revigora com disposição em compreender, valorizar e respeitar a diferença.

Para que haja tolerância é importante também que haja diálogo, uma vez que, por meio dele, existe a possibilidade de se conhecer quem é o próximo e, assim, compreender o porquê tal individuo se comportou ou se comporta de tal maneira. Portanto, os esforços devem se voltar para que o homem seja capaz de promover a abertura para o diálogo, o respeito mútuo e, consequentemente, para o exercício de uma cidadania pautada na cultura da paz.

Nessa perspectiva, a ética é que deverá permear as ações voltadas para a cultura da paz, pois, de acordo com Puig (1998) quando um ser humano se afasta da ética, ele se afasta dos princípios que o norteiam e, da mesma forma a sociedade. $O$ autor ressalta ainda que a educação ética e moral propicia uma análise crítica da realidade cotidiana e das normas sócio morais vigentes, de modo a buscar formas de convivência mais justas e democráticas.

Dessa forma, a tolerância é uma palavra chave nas relações entre as pessoas, apesar das diferenças, nesse caso, pode-se dizer que é preciso saber conviver com e nas situações. Para Delors (2006, pg. 102) enfrentar os desafios do século XXI exige "aprender a viver juntos desenvolvendo a compreensão do outro e a percepção das interdependências - realizar projetos comuns e preparar-se para gerir conflitos - no respeito pelos valores de pluralismo, da compreensão mútua e da paz".

Segundo Puig (1998) a educação moral significa dar forma moral à própria identidade humana, e essa formação depende das circunstâncias que cada indivíduo encontra no seu dia a dia, resultando também em uma vivência coletiva. Assume relevância a compreensão para uma convivência pacificadora e, conforme ressalta Faria (2013), exige aprender a se apoiar mutuamente, a olhar para o outro, a expressar compaixão e tolerância, a confiança, o respeito, a solidariedade e a cooperação no cotidiano, caminhando assim para uma concepção mais humana de cidadania.

Ainda segundo Faria (2013 p. 65) "um bom cidadão reconhece que ele não vive isoladamente, que ele precisa do outro e consequentemente entender que suas ações implicarão também na vida do próximo". Para o autor, a consciência sobre os atos inadequados que se sofre e se comete é o ponto de partida para que a construção do diálogo e da tolerância atinja os níveis pessoais e coletivos nessa convivência, uma tarefa inacabada, para toda vida.

\section{APRENDER A VIVER JUNTOS}

$\mathrm{Na}$ vida, o ser humano pode e tem liberdade de fazer escolhas, mas precisa compreender que suas ações influenciarão todos os que estão a sua volta, sendo assim, os seres humanos devem decidir da melhor forma a maneira que querem viver; isso é necessário porque vivem no mundo em um estado muito incerto e de grande dificuldade, não é possível saber identificar qual será o fim, mas saber fazer acontecer o momento, e com isso delinear parcialmente o futuro.

O trabalho moral situa-se precisamente na necessidade de responder a indeterminação humana. Puig (2007, p. 66) "Procurar uma resposta à pergunta "Como viver"? e aplicá-la à vida individual e coletiva é a tarefa central da moralidade". O autor menciona sobre a importância de uma vida social coletiva, com isso, entende-se também que é preciso aprender a viver juntos.

Dificilmente o ser humano consegue viver isoladamente, ele precisa do outro. Diálogo e tolerância são condições necessárias, são como suportes para assegurar uma boa convivência. A natureza humana almeja aprender a viver de maneira holística, sem se limitar a nenhuma das proporções específicas do viver. Delors (1996); Jonas (1995); Morin (2004) (apud PUIG, 2007, p. 67) contribuem com os seguintes dizeres:

Aprender a viver exige uma educação completa, uma educação que inclua todas as facetas humanas. Uma educação que inclua os principais âmbitos da experiência humana e a aprendizagem ética que cada um deles 
pressupõe: aprender a ser, aprender a conviver, aprender a participar e aprender a habitar o mundo.

Para Morin (2001), é necessário que todos tenham a consciência de que somos cidadãos da Terra e, portanto, nossos destinos estão entrelaçados, exigindo que a humanidade se aproxime de uma ética planetária, comprometida com o destino da humanidade. Explica-se assim a necessidade de ações humanas estarem pautadas em mais dois pilares, "o aprender a participar e o saber habitar o mundo" (PUIG, 2007, p. 72-75).

Aprender a ser refere-se ao processo formativo que cada indivíduo realiza consigo mesmo para liberar-se de certas imposições, para construir uma maneira de ser desejada e para alcançar o maior grau possível de autonomia e de responsabilidade, atingindo a liberdade e interiormente se conhecendo.

Aprender a conviver é uma tarefa educativa que pretende libertar os indivíduos das limitações, ajudando-os a estabelecer vínculos baseados na abertura e na compreensão dos demais, assim, é possível manter conexões pessoais com abertura para compreensão das ações do próximo, permitindo ser tratado com humanidade.

Para viver num mundo multicultural, a qual o indivíduo pertence, é importante que o indivíduo abra sua mente para outras perspectivas diferentes das suas, que tenha capacidade de se colocar no lugar do outro, de valorizar o respeito mútuo, de consolidar relações pautadas no companheirismo, afeto e amizade, compreendendo que cada indivíduo é único e têm suas especificidades na sociedade. Tudo isso poderá ser possível a partir de um diálogo sincero, permanente e solidário, o qual permitirá o indivíduo conhecer melhor seu próximo, respeitando as diferentes formas de ser e viver de cada um.

Nesse sentido, Araújo (2007) ressalta que, cada vez mais, são difundidas no mundo propostas educacionais baseadas na resolução de conflitos, que visam "melhorar o convívio social e criar bases para a construção de sociedades e culturas mais democráticas e sensíveis á ética nas relações humanas" (p.48).

Faria e Souza (2014) ressaltam a necessidade de se trazer para o debate, nas escolas e nos diversos espaços da cidade, a importância do diálogo na construção da cultura da paz, visando ao desenvolvimento humano e uma melhor qualidade de vida. Para tanto, é necessário despertar relações mais horizontais, colaborativas e afetivas, que exigem o saber escutar, ou seja, "colocarse no lugar do outro, abrir-se para a possibilidade do outro em si, sair de sua redoma para o movimento de acolher e crescer com o outro" (p.15).

Os autores ainda chamam a atenção para o fato de que cultura da paz não significa ausência de luta que nega a existência de conflitos e dos seus possíveis enfrentamentos, pelo contrário, se configura como uma "resistência ativa, porém de caráter pacífico e propositivo" (Faria ; Souza 2014, p. 12). Implica, portanto, na aprendizagem da "não indiferença", na prática de ações concretas a partir de opções claras e conscientes contra qualquer tipo de injustiça e discriminação.

Segundo Puig (2007, p 71) "Numa ordem diversa, a abertura para o outro prepara o caminho para a relação cortês e as boas maneiras...", e que acreditamos não estar foram de moda. Sobretudo, é imprescindível o despertar de uma cultura cívica democrática, pautada nos direitos humanos, no respeito mútuo das culturas, bem como "no reconhecimento dos direitos coletivos de todos os povos do planeta". (Delors, 2010, p. 251).

Aprender a participar da vida do outro na forma comum consiste em fazer parte de uma coletividade alcançando um bom nível de ética e civismo, ou respeito pelas normas ou atos públicos, convertendo-se num cidadão ativo. Isto é, ser uma pessoa capaz de exigir os direitos que Ihes correspondem, ao mesmo tempo em que sente a obrigação de cumprir os deveres e manifestar as virtudes cívicas, éticas necessárias que contribuam para a organização democrática 
da convivência. De acordo com Delors (2006) a aprendizagem da vida em comum é uma constante dedicação para ser um cidadão cívico e ativo numa sociedade democrática e participativa.

Nesse ponto de vista, a educação moral cívica desempenha um papel de grande importância na formação integral da pessoa e, segundo Puig $(1998$, p. 9) é imprescindível para:

Ajudar a analisar criticamente a realidade cotidiana e as normas sociomorais vigentes, de modo a ajudar a idealizar formas mais justas e adequadas de convivência. [...] E, finalmente, a educação moral quer formar hábitos de convivência que reforcem valores como a justiça, a solidariedade, a cooperação ou o respeito à natureza.

Dessa forma, a educação moral desempenha um papel de grande valor na formação moral e cívica do cidadão, que socialmente tem muitos direitos, mas também tem deveres para cumprir.

Pode-se dizer que o indivíduo que vive a justiça, a solidariedade e a cooperação citada por Puig (1998), respeita a natureza também, ainda que em processo de aprendizagem, implicará na forma de aprender a viver juntos e a habitar o mundo de forma a privilegiar o espaço de vivência.

Aprender a habitar o mundo significa também assumir uma postura ética que não queira definir uma forma precisa de viver que todo mundo deveria adotar, mas um conjunto de princípios mínimos e de critérios de reflexão que ajude a aproximar posições e entrar em acordo quanto às divergências de ideias. Trata-se de uma ética com valor universal, entendendo como a busca concreta aceitável que ajude o indivíduo a pensar em uma forma de vida que seja sustentável para a humanidade e acima de tudo justa, portanto, que não se sustente na desigualdade social.

\section{RESULTADOS}

A decorrência do diálogo e tolerância é uma boa convivência que liberta os indivíduos e ajuda a estabelecer vínculos. Assim, é possível que haja conexões pessoais providas pelo reconhecimento e valorização do ser humano.

As diferenças sempre existirão na humanidade. Saber viver juntos de forma harmoniosa é justamente compreender e respeitar o próximo, entendendo que sempre há um limite, para que assim se possa viver em um mundo mais humano e moralmente social.

\section{DISCUSSÃO}

É fundamental o despertar de uma cultura civil democrática pautada nos direitos humanos. Entende-se que o ser humano que vive a justiça e a solidariedade, respeita também a vivência do próximo. Saber viver significa também assumir uma postura ética compreendendo que existem direitos e deveres.

Para que haja tolerância é importante que haja também a diálogo. Por meio do diálogo existe a possibilidade de se conhecer o próximo e assim compreender o comportamento do mesmo, já que essa, por sua vez, pode implicar em várias questões, tais como os valores morais, valores éticos e culturais, por isso a importância de se conhecer. Portanto, os esforços devem ser para que o ser humano seja capaz de promover a abertura para o diálogo e tolerância.

\section{CONCLUSÃO}

Este estudo buscou mostrar o diálogo e tolerância como uma possibilidade significativa para a superação da intolerância, preconceitos e discriminações. Por meio do diálogo se aprende o sentido do respeito mútuo e se atinge o reconhecimento do direito à igualdade na diversidade.

Não se pode desconsiderar alguns padrões éticos a serem seguidos para que seja garantida a promoção da pessoa humana, independente de qual grupo, cultura ou classe social ela pertença tampouco se pode negar que o diálogo e tolerância são elementos imprescindíveis para a arte de se viver bem. 
Por fim, reconhece-se que a vida, muito embora particular, proporciona comunhão na adversidade; que o respeito mútuo e o diálogo são ferramentas de mudança social, que possibilitam uma vida mais solidária e comprometida com o equilíbrio entre os indivíduos e a vida do planeta.

O diálogo e tolerância são pilares para se viver bem e agir com força e harmonia em uma sociedade que, muitas vezes, caminha sem saber para onde vai.

Sendo assim, a arte para aprender a viver juntos requer que se rompa com a visão de uma cultura hegemônica e que haja assim, um reconhecimento para com o próximo, valorização e respeito, buscando uma convivência orientada por um código ético construído com o diálogo e tolerância.

\section{REFERÊNCIAS}

ARAÚJO, Ulisses. F. A construção social e psicológica dos valores. In: ARAÚJO, Ulisses. F. PUIG, J. M.; ARANTES, V. A. (Org.). Educação e valores: pontos e contrapontos. São Paulo: Summus, 2007, p. 17-64. (Coleção pontos e contrapontos)

Declaração Universal dos Direitos Coletivos dos Povos. Disponivel em: www.dhnet.org.br/direitos/deconu/a pdf/dec universal direitos coletivos povos.pdf. Acesso: 10/06/2017.

DELORS, J. Educação um tesouro a descobrir. 10. ed. São Paulo: UNESCO, Cortez, 2006.

FARIA, H. SOUZA, V. Convivência e cultura de paz nas cidades / [ organizadores, Hamilton Faria e Valmir de Souza; autores, Hamilton Faria, Martha Lemos, Valmir de Souza ... et al.]. -- São Paulo: Instituto Pólis, 2014. 140 p.

FARIA, H. (Coord.). Cultura Viva, políticas públicas e cultura de paz. São Paulo: Instituto Pólis, 2013.

MARCONI, M. de A.; LAKATOS E. M. Técnicas de pesquisa. São Paulo: editora Atlas S.A 4o edição, 1999.

MORIN, Edgar. Os Sete Saberes necessários à Educação do Futuro. 4ed. São Paulo: Cortez; Brasilia, DF: Unesco, 2001.

PÉREZ SERRANO, G. Educação em valores: como educar para a democracia. 2. ed. Tradução de Fátima Murad. Porto Alegre: Artmed, 2002.

PUIG, Josep M. Aprender a viver. In: In: ARAÚJO, Ulisses. F. PUIG, J. M.; ARANTES, V. A. (Org.). Educação e valores: pontos e contrapontos. São Paulo: Summus, 2007, p. 65-106. (Coleção pontos e contrapontos)

A construção da personalidade moral. 1. ed. São Paulo. Editora Ática, 1998. 